Article

\title{
Measuring Carbon Emissions Performance in 123 Countries: Application of Minimum Distance to the Strong Efficiency Frontier Analysis
}

\author{
Ling Wang ${ }^{1, *}$, Zhongchang Chen ${ }^{2, *}$, Dalai Ma ${ }^{1}$ and Pei Zhao ${ }^{1}$ \\ 1 School of Economics and Business Administration, Chongqing University, Chongqing, 400044, \\ China; E-Mails: madalai@163.com (D.M.); pzhaocqu@163.com (P.Z.) \\ 2 School of Public Affairs, Chongqing University, Chongqing, 400044, China \\ * Authors to whom correspondence should be addressed; E-Mails: 20110201001@cqu.edu.cn (L.W.); \\ cczha@126.com (Z.C.); Tel.: +86-153-2033-0623; +86-133-2026-9111.
}

Received: 6 October 2013; in revised form: 12 November 2013 / Accepted: 22 November 2013 / Published: 9 December 2013

\begin{abstract}
In this paper, we have proposed a general approach to obtain a projection of the nearest targets and minimum distance for a given unit. The method takes undesirable output into account. The idea behind it is that nearest targets and minimum distance lead to less variation in inputs and outputs of the inefficient decision making units (DMUs) being evaluated to reach the production possibility set (PPS) frontier. Our results have shown that the carbon emissions comprehensive performance indexes (CECPIs) of developing countries are lower than those of developed countries, and that the inefficiency shares of energy consumption, capital stock and desirable output are declining while those of labor force and undesirable output are climbing. Further, using cluster analysis, we have shown that nine countries, including Ukraine, Kazakhstan, Uzbekistan and Iraq, should take severe measures to save energy and reduce carbon emissions. Moreover, the gap in CECPIs among the 123 countries is narrowing by kernel density estimation.
\end{abstract}

Keywords: carbon emissions efficiency; minimum distance to the strong efficiency frontier; kernel density estimation; cluster analysis; data envelopment analysis 


\section{Introduction}

Since the 1950s, the advancement of science and technology has greatly boosted the economic growth of the world while harming the environment and increasing global warming. Carbon dioxide is the most common greenhouse gas produced by humans, in 2004 accounting for $76.7 \%$ of all greenhouse gas emissions. More than $80 \%$ of that amount was caused by the burning of fossil fuels (IPCC, 2007) [1]. This has aroused the concern of both scientists and economists.

Study on carbon emissions mainly focuses on four fields: (1) the relations between carbon emissions and the economic growth using the environmental Kuznets curve test [2,3]; (2) the causes of carbon emissions using factor decomposition analysis [4]; (3) analysis of carbon emissions performance using parametric and nonparametric methods [5-7]; and (4) the mechanisms and policies for carbon emissions reduction using macroeconomic models [8].

The assessment of environmental performance begins with the worry about scarcity of energy and carbon dioxide emissions caused by burning fossil fuels. In 1993, Kaya and Yokobori first put forward the concept of carbon productivity [9]. They explored carbon emissions performance (CEP) by data envelopment analysis (DEA). DEA is a nonparametric technique for assessing the performance or efficiency of DMUs, which has led to the development of a thousand models at present [10,11]. It ranges from the traditional DEA methods (such as CCR, BCC and the additive models) to models which seek the nearest target projection.

Traditional DEA methods may be divided into two classes. These include: (1) radial models: in these models (e.g., CCR and BBC), defining the reach of the PPS frontier requires reducing/adding proportionally the inputs/outputs of the unit being assessed and (2) nonradial models: in these models (e.g., additive models and slack based measure (SBM) models), defining the reach of the PPS frontier requires reducing/adding the weighted sum of the variables to the maximum. For the efficient projection to the DMU under assessment it is not always certain whether it is the closest strong efficient unit in the above-mentioned models. By contrast, SBM and additive models choose the farthest strong efficient unit among all strong efficient units (also called efficient projections on the frontier) dominating the efficiency of DMU under assessment [12]. Using minimum distance to the strong efficiency frontier method can make the DMUs being assessed reach the frontier with less improvement in inputs and outputs. This method is employed in this paper to compute the CEP.

In the literature on CEP, several important problems have not been solved. How should each country be incorporated into one overall production system [13-18]? How should CEP be evaluated more realistically? How should emissions reduction policies for these countries be adjusted? This paper uses minimum distance to the strong efficiency frontier model, which takes the undesirable output into account, to measure CEP and address the issues above.

This paper contributes to the literature in two ways. First, it represents the first attempt to bring every country into one production system for analysis. Second, the measure employed in this paper can help inefficient countries to improve their efficiency and achieve their optimal production objectives with less effort.

The remainder of this paper is organized as follows. In the following section we develop a general approach for obtaining the nearest target for a DMU which consumes multiple inputs to produce 
desirable and undesirable outputs. Section 3 includes the data sources and the empirical results. The last section presents discussions and conclusions.

\section{Methodology}

Based upon the minimum distance to the strong efficiency frontier method of Jahanshahloo et al., 2012 [12] and Aparicio et al., 2007 [19] in which they minimized the $\mathrm{L}_{1}$-distance (the L1 is an Euclidean norm whose definition is $\|X\|_{1}=\left|X_{1}\right|+\left|X_{1}\right|+\cdots+\left|X_{n}\right|$ ) to seek the optimal projection and compute efficiency, this paper puts forward a new minimum distance to the strong efficiency frontier method that considers undesirable outputs.

\subsection{Strong Efficient Unit}

Strong efficiency is also called Pareto efficiency. For multi-objective programming, if an evaluated unit is effective, we call it a Pareto efficient unit.

Suppose in the PPS, $\mathrm{P}$ is represented as $P=\{(x, y): x$ can produce $y\}$.

Define: $D M U_{0}=\left(x_{0}, y_{0}\right)$ is called a strong efficient unit in $\mathrm{P}$ only if there is no other $(x, y) \in P$ like $(x, y) \leq\left(x_{0}, y_{0}\right)$ and at least one holds for strict inequality.

Regarding the above definition, a unit in $\mathrm{P}$ is a strong efficient unit in $\mathrm{P}$ if it is impossible to improve any of its inputs and outputs without worsening other units.

\subsection{Carbon Emissions Production Technology}

Let that the production system have $n$ DMUs. Each DMU uses $m$ inputs to produce $s_{l}$ desirable outputs and $s_{2}$ undesirable outputs. Matrix $X=\left(x_{1}, x_{2}, \ldots, x_{n}\right) \in R_{+}^{m \times n}, Y^{g}=\left(y_{1}^{g}, y_{2}^{g} \ldots, y_{n}^{g}\right) \in R_{+}^{s_{1} \times n}$, $Y^{b}=\left(y_{1}^{b}, y_{2}^{b} \ldots, y_{n}^{b}\right) \in R_{+}^{s_{2} \times n}$ represent input, desirable output, and undesirable output variables, respectively. Assume $D M U_{0}=\left(x_{0}, y_{0}^{g}, y_{0}^{b}\right)$ as the unit under assessment and $F^{s}(P)$ to be the strong efficient frontier of $\mathrm{P}$. The minimum distance to the strong efficiency frontier problem may then be modeled as follows:

$$
\begin{aligned}
&(m S B M) \quad \min \left[\left(\sum_{i=1}^{m} s_{i 0}^{-}+\sum_{r=1}^{s_{1}} s_{r 0}^{+}+\sum_{l=1}^{s_{2}} s_{l 0}^{-}\right)+M\left(\sum_{i=1}^{m} \bar{s}_{i 0}^{-}+\sum_{r=1}^{s_{1}} \bar{s}_{r 0}^{+}+\sum_{l=1}^{s_{2}} \overline{s_{l 0}^{-}}\right)\right. \\
& s_{i 0}^{-} \geq 0, i=1, \ldots, m \\
& s_{r 0}^{+} \geq 0, r=1, \ldots, s_{1} \\
& s_{l 0}^{-} \geq 0, l=1, \ldots, s_{2} \\
& \max \left(\sum_{i=1}^{m} \bar{s}_{i 0}^{-}+\sum_{r=1}^{s} \bar{s}_{r 0}^{+}+\sum_{l=1}^{s_{2}} \overline{s_{l 0}^{-}}\right) \\
& \text {s.t. } \sum_{j \in E_{c}} \lambda_{j} x_{i j}+\bar{s}_{i 0}^{-}=x_{i 0}-s_{i 0}^{-} \\
& \sum_{j \in E_{c}} \lambda_{j} y_{i j}^{g}-\bar{s}_{r 0}^{+}=y_{i 0}^{g}+s_{r 0}^{+} \\
& \sum_{j \in E_{c}} \lambda_{j} y_{i j}^{b}+\bar{s}_{l 0}^{-}=y_{i 0}^{b}-\bar{s}_{l 0}^{-} \\
& \lambda_{j} \geq 0, \bar{s}_{i 0}^{-} \geq 0, \bar{s}_{r 0}^{+} \geq 0, \bar{s}_{l 0}^{-} \geq 0
\end{aligned}
$$


where $s_{i 0}^{-}, s_{r 0}^{+}, s_{l 0}^{-}, \bar{s}_{i 0}^{-}, \bar{s}_{r 0}^{+}, \bar{s}_{l 0}^{-}$represent the slack variables, $\mathrm{M}$ is a sufficiently large real number. The above problem is a linear bilevel programming problem (LBP), called (mSBM) to emphasize that it follows the idea of the SBM model [20], but minimizing instead of maximizing the $\mathrm{L}_{1}$-distance at the objective. Thus, it can offer the corresponding closest targets according to this distance. If the objective in the second program of Equation (2) is replaced as follows:

$$
\min \left(\frac{1-\frac{1}{m} \sum_{i=1}^{m} \bar{s}_{i 0}^{-} / x_{i 0}}{1+\frac{1}{s_{1}+s_{2}}\left(\sum_{r=1}^{s_{1}} \bar{s}_{r 0}^{+} / y_{r 0}+\sum_{l=1}^{s_{2}} \bar{s}_{l 0}^{-} / b_{l 0}\right)}\right)
$$

Then the second program of LBP will be called SBM. To achieve Equation (3), the bigger the values of $\sum_{i=1}^{m} \bar{s}_{i 0}^{-} / x_{i 0}, \sum_{r=1}^{s_{1}} \bar{s}_{r 0}^{+} / y_{r 0}, \sum_{l=1}^{s_{2}} \bar{s}_{l 0}^{-} / b_{l 0}$ are, the better. Moreover, the denominators of these three values are constant. As long as the slack variables ${\overline{s_{i 0}}}_{i},{\overline{s_{r 0}}}_{r 0}^{+} \bar{s}_{l 0}^{-}$grow in size, the objective of Equation (3) will decrease. Therefore, the SBM represents the maximum distance to the strong efficiency frontier model.

We should also note that the (mSBM) model with the characterization of a strong efficiency unit remains immutable: the necessary and sufficient condition of $\mathrm{DMU}_{0}$ being a strong efficiency unit is that the optimal slacks in (mSBM) are all zero. Hence, this model may be used instead of the classical SBM in this paper, since it has the advantage of obtaining the nearest targets and minimum distance of a DMU from the strong efficient frontier.

\subsection{Carbon Emissions Performance Indexes}

In order to derive carbon emissions performance indexes, we first have to explicitly define the input and output variables. In this paper, the input vector $x$ contains capital (K), labor (L), and energy (E), while the desirable output $y$ refers to the GDP of each country (or region) and the undesirable output $b$ is carbon dioxide emissions. Since there are three inputs and two outputs, we set the weight vectors to be $(1 / 6,1 / 6,1 / 6,1 / 4,1 / 4)$. Therefore, we can define input inefficiency, desirable output inefficiency, and undesirable output inefficiency based on Cooper et al., 2007 [21] as follows:

Input inefficiency:

$$
I E_{x}=\frac{1}{2 m} \sum_{i=1}^{m} s_{i 0}^{-} / x_{i o}
$$

Desirable output inefficiency:

$$
I E_{y}=\frac{1}{4 s_{1}} \sum_{r=1}^{s_{1}} s_{r 0}^{y+} / y_{r 0}
$$

Undesirable output inefficiency:

$$
I E_{b}=\frac{1}{4 s_{2}} \sum_{l=1}^{s_{2}} s_{l 0}^{b-} / b_{l 0}
$$


Carbon emissions inefficiency:

$$
I E=I E_{x}+I E_{y}+I E_{b}
$$

Thus $\frac{I E_{x}}{I E}, \frac{I E_{y}}{I E}, \frac{I E_{b}}{I E}$ are the inefficiency contribution ratios of the input, desirable output, and undesirable output respectively. $s_{i 0}^{-} / x_{i 0}, s_{r 0}^{y+} / y_{r 0}, s_{l}^{b-} / b_{l o}$ are the percentages of improvement.

With reference to formulas (4)-(6), we obtain the CECPI as follows:

$$
\theta=\frac{1-\text { Input inefficien cy }}{1+\text { Output inefficien cy }}
$$

The following example shows the advantage of the (mSBM) model in determining the efficiency score. Consider $\mathrm{DMU}_{1}$ to $\mathrm{DMU}_{8}$ with three inputs $\left(x_{1}, x_{2}, x_{3}\right)$, one desirable output $(y)$ and one undesirable output $(b)$ as the observed DMUs. Table 1 provides the CECPIs of the DMUs in the SBM and (mSBM) models. For these DMUs, we have reported the original values of all variables in the first row. The target values by SBM measure are shown in the second row. In third row the same information is provided by $(\mathrm{mSBM})$ measure. We have also calculated the percentage of improvement in each variable, reported in parentheses in order to make comparisons among targets easier.

Table 1 shows that, by the SBM model, an improvement of $32 \%$ for $x_{1}, 46 \%$ for $x_{2}, 5 \%$ for $x_{3}$, and $40 \%$ for $\mathrm{b}$ can help DMU1 reach the optimal PPS frontier. For the (mSBM) model, a much lower improvement of $9 \%$ for $x_{1}, 10 \%$ for $x_{2}$ and $9 \%$ for $y$ enables DMU1 to reach the optimal PPS frontier. DMU4 and DMU8 are identical. Reaching the optimal PPS frontier with massive decreases/increases in inputs/outputs (where outputs are desirable outputs, and the undesirable outputs are considered to be same as inputs which need to be decreased) is very difficult in practice. However, when slight improvements can help reach the optimal PPS frontier, it may be useful for any economic entity.

As the analysis above shows, the general argument behind this idea is that the (mSBM) model is able to obtain the closest projection for the assessed DMU, while the SBM model leads to a projection that is at maximum distance. Thus, the (mSBM) measure allows an inefficient DMU to improve its efficiency in the easiest manner, which supports more practical policies.

Table 1. CECPI by the slack based measure (SBM) and (mSBM) models.

\begin{tabular}{cccccccc}
\hline DMU & & $x_{1}$ & $x_{2}$ & $x_{3}$ & $y$ & $b$ & $\theta$ \\
\hline & original values & 28.1 & 4.6 & 31 & 12.6 & 6.3 & \\
$\mathbf{1}$ & SBM & $19.2(32 \%)$ & $2.5(46 \%)$ & $29.5(5 \%)$ & $12.6(0 \%)$ & $3.7(40 \%)$ & 0.604 \\
& mSBM & $25.6(9 \%)$ & $4.2(10 \%)$ & $31(0 \%)$ & $13.7(9 \%)$ & $6.3(0 \%)$ & 0.897 \\
\hline \multirow{4}{*}{4} & original values & 15 & 11.1 & 36.5 & 10.5 & 5.1 & \\
& SBM & $15(0 \%)$ & $3.9(65 \%)$ & $26.8(26 \%)$ & $10.5(0 \%)$ & $2.7(47 \%)$ & 0.564 \\
& mSBM & $15(0 \%)$ & $8.8(20 \%)$ & $36.5(0 \%)$ & $12(15 \%)$ & $2.2(56 \%)$ & 0.687 \\
\hline \multirow{2}{*}{$\mathbf{8}$} & original values & 19.8 & 4 & 23 & 9 & 5.1 & \\
& SBM & $13.7(31 \%)$ & $1.8(55 \%)$ & $21(8 \%)$ & $9(0 \%)$ & $2.7(47 \%)$ & 0.553 \\
& $\mathbf{m S B M}$ & $19.8(0 \%)$ & $3.4(16 \%)$ & $22.3(3 \%)$ & $10(12 \%)$ & $5.1(0 \%)$ & 0.885 \\
\hline
\end{tabular}

Note: In view of space limitations, Table 1 here only presents calculated values of DMU efficiencies which are less than 1; Numbers not in parentheses in the row of SBM and mSBM are the target values by SBM and mSBM measure respectively, and in parentheses are the efficiency improvement percentages. 


\section{Empirical Analysis}

\subsection{Data and Its Descriptive Statistics Analysis}

The data on the five variables including K, L, E, Y and b of 123 countries or regions (see Appendix). Data for the period 1992-2009 for the listed countries and regions (hereafter "countries") were collected for the current study. Some countries were not considered due to the unavailability or inconsistency of their data. Data for K, L, and Y come from the Penn World Table Version 8.0 while data for the other variables come from the World Bank online database. Table 2 provides detailed information on these five variables and Table 3 shows descriptive statistics of the input and output variables.

Table 2. Definition of variables.

\begin{tabular}{ll}
\hline Variable & Data compilation \\
\hline Capital stock (K) & $\begin{array}{l}\text { At current purchasing power parities (PPPs) (in millions at 2005 prices) } \\
\text { Lumber of persons engaged (in millions) } \\
\text { Refers to use of primary energy before transformation to other end-use fuels, } \\
\text { Energy consumption (E) }\end{array}$ \\
$\begin{array}{l}\text { Dhich is equal to indigenous production plus imports and stock changes, minus } \\
\text { exports and fuels supplied to ships and aircraft engaged in international transport. }\end{array}$ \\
$\begin{array}{l}\text { Uses expenditure-side real GDP at chained PPPs (in millions at 2005 prices) } \\
\text { Uses Carbon dioxide emissions which are those stemming from the burning of } \\
\text { fossil fuels and the manufacture of cement. They include carbon dioxide produced } \\
\text { during consumption of solid, liquid, and gas fuels and gas flaring. }\end{array}$ \\
\hline
\end{tabular}

Table 3. Descriptive statistics of inputs and outputs. SD: Standard deviation.

\begin{tabular}{cccccc}
\hline Variable & Unit & Mean & SD & Min & Max \\
\hline K & \$1 million & $1,851,566.30$ & $5,381,598.77$ & $9,693.44$ & $41,251,352.00$ \\
L & $10^{6}$ workers & 23.06 & 83.02 & 0.17 & 777.38 \\
E & $10^{3}$ tons & $92,995.80$ & $293,928.85$ & 799.60 & $2,257,100.88$ \\
Y & $\$ 1$ million & $524,979.04$ & $1,535,226.62$ & $5,136.00$ & $12,839,243.00$ \\
b & $10^{3}$ tons & $239,703.89$ & $866,647.14$ & $1,485.14$ & $7,687,113.77$ \\
\hline
\end{tabular}

\subsection{Carbon Emissions Comprehensive Performance}

We first computed CECPIs for 123 countries using Equations (1-2). The results are given in Table 4 and Figures 1 and 2. Table 4 shows that Hong Kong, Zimbabwe, Costa Rica, Luxembourg, Switzerland, Sudan, Ireland, United Kingdom, Panama and Sweden rank among the top 10 countries in the world in terms of CECPI. Among these only the United Kingdom's GDP ranks among the top ten, while none of the others falls into the top thirty. Hong Kong has the highest CECPI possibly because Hong Kong's industry only accounts for a rather small share of its GDP. The Russian Federation, China, and India, whose GDPs rank top 10 in the world, have very low CECPIs $(0.620,0.651$, and 0.701, respectively). The CECPIs of China and the Russian Federation are 102nd and 109th in the world, respectively. Developing countries like China and India are at the stage of industrial expansion and their economies follow the same economic development style in which growing the economy takes precedence over pollution regulation. Since the Russian Federation has considerable heavy industry characterized by huge capital inputs, huge energy consumption, and heavy pollution, its 
CECPI is inevitably low. The 10 lowest CECPIs belong to Kazakhstan, Turkmenistan, Syria, Moldova, El Salvador, Mongolia, Ukraine, Mozambique, Nigeria and Congo. Most of these countries are developing nations. Twenty-four developed countries, including Germany, France, United Kingdom, Italy, Spain, Netherlands, Belgium, Switzerland, Sweden, Austria, Greece, Norway, Portugal, Denmark, Finland, Ireland, Luxembourg, Iceland, Japan, Singapore, United States, Canada, Australia, and New Zealand have higher CECPIs, ranging from 0.8 to 1 .

Figure 1 shows the trend of CECPIs in countries whose GDP ranks among the top 10 in the world for the study period (1992-2009). In general, their CECPIs fluctuate a bit, with six climbing somewhat while four (China, Japan, Brazil and Italy) decline. The Russian Federation, the US, and China exhibit greater fluctuation. These fluctuations may come from changes in technology, economic growth capacity, industrial structure, international trade, investment structure and other factors. For example, in China, the CECPI of 2009 declined, due to the 4 trillion Yuan in infrastructure investment that year, since construction causes heavy pollution.

Table 4. Average carbon emissions comprehensive performance index (CECPI) and rank in 123 countries from 1992 to 2009.

\begin{tabular}{|c|c|c|c|c|c|c|c|c|}
\hline No. & C.C. & $\theta$ & No. & C.C. & $\theta$ & No. & C.C. & $\theta$ \\
\hline 1 & USA & $0.887(26)$ & 42 & KAZ & $0.591(114)$ & 83 & SVN & $0.837(38)$ \\
\hline 2 & $\mathrm{CHN}$ & $0.651(102)$ & 43 & CHL & $0.859(32)$ & 84 & CRI & $0.992(3)$ \\
\hline 3 & IND & $0.701(83)$ & 44 & PER & $0.733(74)$ & 85 & PAN & $0.96(9)$ \\
\hline 4 & JPN & $0.856(34)$ & 45 & NOR & $0.905(20)$ & 86 & URY & $0.898(22)$ \\
\hline 5 & DEU & $0.892(25)$ & 46 & $\mathrm{CZE}$ & $0.757(68)$ & 87 & BOL & $0.718(76)$ \\
\hline 6 & RUS & $0.62(109)$ & 47 & PRT & $0.858(33)$ & 88 & LUX & $0.979(4)$ \\
\hline 7 & FRA & $0.907(18)$ & 48 & BGD & $0.761(64)$ & 89 & CMR & $0.924(11)$ \\
\hline 8 & GBR & $0.96(8)$ & 49 & QAT & $0.765(62)$ & 90 & NPL & $0.871(31)$ \\
\hline 9 & BRA & $0.808(47)$ & 50 & DNK & $0.894(23)$ & 91 & LVA & $0.787(53)$ \\
\hline 10 & ITA & 0.907 (17) & 51 & ISR & $0.88(28)$ & 92 & JOR & $0.606(112)$ \\
\hline 11 & MEX & $0.853(35)$ & 52 & HUN & $0.826(39)$ & 93 & PRY & $0.815(43)$ \\
\hline 12 & ESP & $0.893(24)$ & 53 & FIN & $0.773(57)$ & 94 & $\mathrm{BIH}$ & $0.682(92)$ \\
\hline 13 & KOR & $0.811(45)$ & 54 & KWT & $0.756(69)$ & 95 & ZMB & $0.67(95)$ \\
\hline 14 & CAN & 0.815 & 55 & UZB & $0.622(108)$ & 96 & CIV & $0.808(48)$ \\
\hline 15 & TUR & $0.924(12)$ & 56 & IRL & $0.964(7)$ & 97 & BRN & $0.915(14)$ \\
\hline 16 & IDN & $0.761(65)$ & 57 & BLR & $0.667(97)$ & 98 & BHR & $0.614(110)$ \\
\hline 17 & IRN & $0.686(90)$ & 58 & IRQ & $0.638(105)$ & 99 & TTO & $0.736(73)$ \\
\hline 18 & AUS & $0.811(46)$ & 59 & NZL & $0.872(30)$ & 100 & EST & $0.684(91)$ \\
\hline 19 & SAU & $0.682(93)$ & 60 & MAR & $0.666(98)$ & 101 & GEO & $0.695(86)$ \\
\hline 20 & POL & $0.743(71)$ & 61 & SVK & $0.774(56)$ & 102 & BWA & $0.845(37)$ \\
\hline 21 & NLD & $0.906(19)$ & 62 & ECU & $0.703(82)$ & 103 & ALB & $0.748(70)$ \\
\hline 22 & ARG & $0.759(67)$ & 63 & LKA & $0.92(13)$ & 104 & CYP & $0.801(51)$ \\
\hline 23 & THA & $0.673(94)$ & 64 & BGR & $0.699(84)$ & 105 & HND & $0.769(59)$ \\
\hline 24 & PAK & $0.761(63)$ & 65 & OMN & $0.771(58)$ & 106 & COD & $0.433(123)$ \\
\hline 25 & $\mathrm{ZAF}$ & $0.668(96)$ & 66 & DOM & $0.796(52)$ & 107 & $\mathrm{MOZ}$ & $0.512(121)$ \\
\hline 26 & EGY & $0.823(41)$ & 67 & AZE & $0.602(113)$ & 108 & GAB & $0.848(36)$ \\
\hline 27 & $\mathrm{COL}$ & $0.804(50)$ & 68 & SDN & $0.975(6)$ & 109 & SEN & $0.634(106)$ \\
\hline 28 & MYS & $0.71(78)$ & 69 & AGO & $0.644(103)$ & 110 & MKD & $0.651(101)$ \\
\hline
\end{tabular}


Table 4. Cont.

\begin{tabular}{ccccccccc}
\hline No. & C.C. & $\theta$ & No. & C.C. & $\theta$ & No. & C.C. & $\theta$ \\
\hline 29 & BEL & $0.876(29)$ & 70 & SYR & $0.565(116)$ & 111 & TJK & $0.691(87)$ \\
30 & NGA & $0.467(122)$ & 71 & HRV & $0.825(40)$ & 112 & ARM & $0.713(77)$ \\
31 & UKR & $0.52(120)$ & 72 & TUN & $0.766(61)$ & 113 & MNG & $0.529(119)$ \\
32 & CHE & $0.977(5)$ & 73 & ETH & $0.632(107)$ & 114 & JAM & $0.706(81)$ \\
33 & SWE & $0.934(10)$ & 74 & TKM & $0.573(115)$ & 115 & MDA & $0.56(117)$ \\
34 & PHL & $0.767(60)$ & 75 & GHA & $0.759(66)$ & 116 & NAM & $0.805(49)$ \\
35 & AUT & $0.915(15)$ & 76 & GTM & $0.91(16)$ & 117 & KGZ & $0.698(85)$ \\
36 & VNM & $0.709(79)$ & 77 & TZA & $0.688(88)$ & 118 & BEN & $0.709(80)$ \\
37 & VEN & $0.652(100)$ & 78 & LTU & $0.775(55)$ & 119 & ISL & $0.737(72)$ \\
38 & ROU & $0.686(89)$ & 79 & LBN & $0.64(104)$ & 120 & COG & $0.719(75)$ \\
39 & HKG & $1(1)$ & 80 & ZWE & $0.999(2)$ & 121 & MLT & $0.881(27)$ \\
40 & GRC & $0.819(42)$ & 81 & KEN & $0.785(54)$ & 122 & SLV & $0.557(118)$ \\
41 & SGP & $0.898(21)$ & 82 & YEM & $0.664(99)$ & 123 & TGO & $0.609(111)$ \\
\hline
\end{tabular}

Note: C.C. is the abbreviation of country code. Numbers in parentheses refer to the world rankings of each CECPI, and sequence numbers from 1 to123 reflect GDP ranking.

Figure 1. CECPI trends for top 10 GDPs.

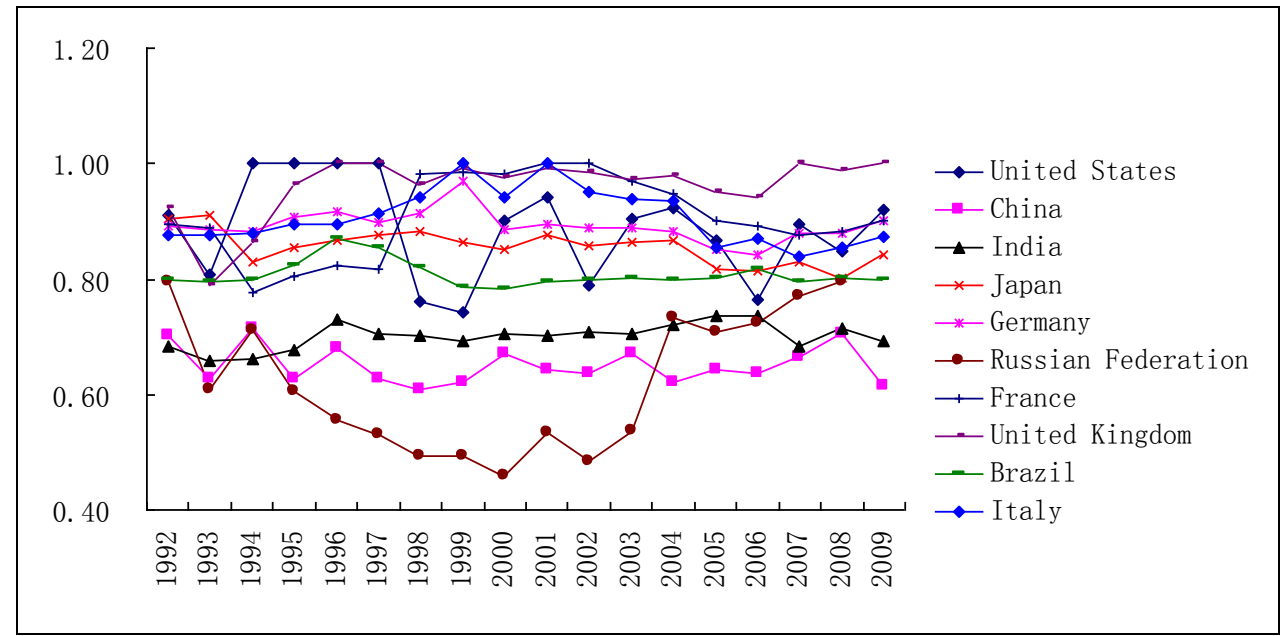

\subsection{Carbon Emissions Inefficiency Analysis}

Table 5 provides efficiency improvement percentages and inefficiency contribution ratios of the top 10 GDPs in 1992 and 2009 respectively. We found that their efficiency improvements in inputs and outputs have changed greatly since 1992. For China, in 1992, the main inefficiency came from the Labor force (L) contribution; while in 2009, it came from Undesirable output (b). For Brazil, in 1992, capital stock (K) made the leading contribution to inefficiency, while in 2009, the lack of GDP output (y) and excessive emissions (b) were the main causes. The means of 123 countries show that the inefficiency contributions of $\mathrm{E}, \mathrm{K}$ and $\mathrm{Y}$ are declining while those of $\mathrm{L}$ and $\mathrm{b}$ are climbing. 
Table 5. Efficiency improvements and inefficiencies of the main countries.

\begin{tabular}{|c|c|c|c|c|c|c|c|c|c|c|}
\hline & \multicolumn{5}{|c|}{1992} & \multicolumn{5}{|c|}{2009} \\
\hline & $\mathbf{E}$ & $\mathbf{L}$ & $\mathbf{K}$ & $\mathbf{Y}$ & B & $\mathbf{E}$ & $\mathbf{L}$ & $\mathbf{K}$ & $\mathbf{Y}$ & b \\
\hline USA & $\begin{array}{c}10.7 \% \\
(39.9 \%) \\
\end{array}$ & $\begin{array}{c}0 \% \\
(0 \%) \\
\end{array}$ & $\begin{array}{c}16.2 \% \\
(60.2 \%) \\
\end{array}$ & $\begin{array}{c}0 \% \\
(0 \%) \\
\end{array}$ & $\begin{array}{c}0 \% \\
(0 \%) \\
\end{array}$ & $\begin{array}{c}0.5 \% \\
(2.5 \%) \\
\end{array}$ & $\begin{array}{c}0 \% \\
(0 \%) \\
\end{array}$ & $\begin{array}{c}5.2 \% \\
(27.8 \%) \\
\end{array}$ & $\begin{array}{c}13.1 \% \\
(69.7 \%) \\
\end{array}$ & $\begin{array}{c}0 \% \\
(0 \%) \\
\end{array}$ \\
\hline $\mathbf{C H N}$ & $\begin{array}{c}0 \% \\
(0 \%) \\
\end{array}$ & $\begin{array}{c}89 \% \\
(99.5 \%) \\
\end{array}$ & $\begin{array}{c}0 \% \\
(0 \%) \\
\end{array}$ & $\begin{array}{c}0 \% \\
(0 \%) \\
\end{array}$ & $\begin{array}{c}0.5 \% \\
(0.52 \%) \\
\end{array}$ & $\begin{array}{c}27.4 \% \\
(22.2 \%) \\
\end{array}$ & $\begin{array}{c}0 \% \\
(0 \%) \\
\end{array}$ & $\begin{array}{c}0 \% \\
(0 \%) \\
\end{array}$ & $\begin{array}{c}8.9 \% \\
(7.2 \%) \\
\end{array}$ & $\begin{array}{c}87 \% \\
(70.6 \%) \\
\end{array}$ \\
\hline IND & $\begin{array}{c}0 \% \\
(0 \%) \\
\end{array}$ & $\begin{array}{l}2.8 \% \\
(3 \%) \\
\end{array}$ & $\begin{array}{c}0 \% \\
(0 \%) \\
\end{array}$ & $\begin{array}{c}0 \% \\
(0 \%) \\
\end{array}$ & $\begin{array}{l}90.4 \% \\
(97 \%) \\
\end{array}$ & $\begin{array}{c}0 \% \\
(0 \%) \\
\end{array}$ & $\begin{array}{c}81.8 \% \\
(89.2 \%) \\
\end{array}$ & $\begin{array}{c}0 \% \\
(0 \%) \\
\end{array}$ & $\begin{array}{c}0 \% \\
(0 \%) \\
\end{array}$ & $\begin{array}{c}9.9 \% \\
(10.8 \%) \\
\end{array}$ \\
\hline JPN & $\begin{array}{c}0 \% \\
(0 \%)\end{array}$ & $\begin{array}{c}1.9 \% \\
(8.8 \%)\end{array}$ & $\begin{array}{c}0 \% \\
(0 \%)\end{array}$ & $\begin{array}{c}19.5 \% \\
(91.2 \%)\end{array}$ & $\begin{array}{c}0 \% \\
(0 \%)\end{array}$ & $\begin{array}{c}0 \% \\
(0 \%)\end{array}$ & $\begin{array}{c}0 \% \\
(0 \%)\end{array}$ & $\begin{array}{l}47.4 \% \\
(100 \%)\end{array}$ & $\begin{array}{c}0 \% \\
(0 \%)\end{array}$ & $\begin{array}{c}0 \% \\
(0 \%)\end{array}$ \\
\hline DEU & $\begin{array}{c}0 \% \\
(0 \%) \\
\end{array}$ & $\begin{array}{c}0 \% \\
(0 \%) \\
\end{array}$ & $\begin{array}{c}31.8 \% \\
(98.7 \%) \\
\end{array}$ & $\begin{array}{c}0 \% \\
(0 \%) \\
\end{array}$ & $\begin{array}{c}0.4 \% \\
(1.3 \%) \\
\end{array}$ & $\begin{array}{c}0 \% \\
(0 \%) \\
\end{array}$ & $\begin{array}{c}0 \% \\
(0 \%) \\
\end{array}$ & $\begin{array}{c}30 \% \\
(100 \%) \\
\end{array}$ & $\begin{array}{c}0 \% \\
(0 \%) \\
\end{array}$ & $\begin{array}{c}0 \% \\
(0 \%) \\
\end{array}$ \\
\hline RUS & $\begin{array}{c}9.5 \% \\
(15.5 \%) \\
\end{array}$ & $\begin{array}{c}0 \% \\
(0 \%) \\
\end{array}$ & $\begin{array}{c}51.7 \% \\
(84.5 \%)\end{array}$ & $\begin{array}{c}0 \% \\
(0 \%) \\
\end{array}$ & $\begin{array}{c}0 \% \\
(0 \%) \\
\end{array}$ & $\begin{array}{c}17.8 \% \\
(29.1 \%) \\
\end{array}$ & $\begin{array}{c}0 \% \\
(0 \%) \\
\end{array}$ & $\begin{array}{c}43.2 \% \\
(70.9 \%) \\
\end{array}$ & $\begin{array}{c}0 \% \\
(0 \%) \\
\end{array}$ & $\begin{array}{c}0 \% \\
(0 \%) \\
\end{array}$ \\
\hline FRA & $\begin{array}{c}20.2 \% \\
(64.8 \%) \\
\end{array}$ & $\begin{array}{c}10.8 \% \\
(34.6 \%) \\
\end{array}$ & $\begin{array}{c}0 \% \\
(0 \%) \\
\end{array}$ & $\begin{array}{c}0.2 \% \\
(0.52 \%) \\
\end{array}$ & $\begin{array}{c}0 \% \\
(0 \%) \\
\end{array}$ & $\begin{array}{c}0 \% \\
(0 \%) \\
\end{array}$ & $\begin{array}{c}0 \% \\
(0 \%) \\
\end{array}$ & $\begin{array}{c}24.7 \% \\
(86.8 \%) \\
\end{array}$ & $\begin{array}{c}3.75 \% \\
(13.2 \%) \\
\end{array}$ & $\begin{array}{c}0 \% \\
(0 \%) \\
\end{array}$ \\
\hline GBR & $\begin{array}{c}0 \% \\
(0 \%) \\
\end{array}$ & $\begin{array}{c}0 \% \\
(0 \%) \\
\end{array}$ & $\begin{array}{l}16.84 \% \\
(79.7 \%) \\
\end{array}$ & $\begin{array}{c}0 \% \\
(0 \%) \\
\end{array}$ & $\begin{array}{c}4.3 \% \\
(20.3 \%) \\
\end{array}$ & $\begin{array}{c}0 \% \\
(0 \%) \\
\end{array}$ & $\begin{array}{c}0 \% \\
(0 \%) \\
\end{array}$ & $\begin{array}{c}0 \% \\
(0 \%) \\
\end{array}$ & $\begin{array}{c}0 \% \\
(0 \%) \\
\end{array}$ & $\begin{array}{c}0 \% \\
(0 \%) \\
\end{array}$ \\
\hline BRA & $\begin{array}{c}0 \% \\
(0 \%) \\
\end{array}$ & $\begin{array}{c}0 \% \\
(0 \%)\end{array}$ & $\begin{array}{c}60.1 \% \\
(100 \%) \\
\end{array}$ & $\begin{array}{c}0 \% \\
(0 \%) \\
\end{array}$ & $\begin{array}{c}0 \% \\
(0 \%) \\
\end{array}$ & $\begin{array}{c}0 \% \\
(0 \%) \\
\end{array}$ & $\begin{array}{c}0 \% \\
(0 \%) \\
\end{array}$ & $\begin{array}{c}0 \% \\
(0 \%) \\
\end{array}$ & $\begin{array}{c}37.4 \% \\
(74.6 \%)\end{array}$ & $\begin{array}{c}12.7 \% \\
(25.4 \%) \\
\end{array}$ \\
\hline ITA & $\begin{array}{c}0.1 \% \\
(0.2 \%) \\
\end{array}$ & $\begin{array}{c}0 \% \\
(0 \%) \\
\end{array}$ & $\begin{array}{c}37 \% \\
(99.8 \%) \\
\end{array}$ & $\begin{array}{c}0 \% \\
(0 \%) \\
\end{array}$ & $\begin{array}{c}0 \% \\
(0 \%) \\
\end{array}$ & $\begin{array}{c}0 \% \\
(0 \%) \\
\end{array}$ & $\begin{array}{c}0 \% \\
(0 \%) \\
\end{array}$ & $\begin{array}{c}37.8 \% \\
(100 \%) \\
\end{array}$ & $\begin{array}{c}0 \% \\
(0 \%) \\
\end{array}$ & $\begin{array}{c}0 \% \\
(0 \%) \\
\end{array}$ \\
\hline mean & $\begin{array}{c}8.7 \% \\
(11.3 \%)\end{array}$ & $\begin{array}{l}5.3 \% \\
(7 \%) \\
\end{array}$ & $\begin{array}{c}18.6 \% \\
(29.9 \%)\end{array}$ & $\begin{array}{c}18 \% \\
(30.2 \%)\end{array}$ & $\begin{array}{c}11.3 \% \\
(12.7 \%)\end{array}$ & $\begin{array}{c}3.2 \% \\
(4.3 \%)\end{array}$ & $\begin{array}{c}12.7 \% \\
(14.3 \%)\end{array}$ & $\begin{array}{c}14.6 \% \\
(27.7 \%)\end{array}$ & $\begin{array}{c}12.4 \% \\
(23.7 \%)\end{array}$ & $\begin{array}{c}11.5 \% \\
(16.2 \%)\end{array}$ \\
\hline
\end{tabular}

Note: Mean obtained by averaging 123 countries. Numbers not in parentheses are efficiency improvement percentages and in parentheses are inefficiency contribution ratios.

\subsection{Cluster Analysis}

With the help of SPSS17.0 software [22], we employ K-Means clustering to divide all the countries by CECPI into the high efficiency zone, medium efficiency zone, low efficiency zone, and by emissions intensity into the high-intensity zone, medium intensity zone and low intensity zone, respectively. Details are given in Table 6 . The 41 countries in the high efficiency zone are also in the low-intensity zone with relatively better CECPIs. UKR, KAZ, UZB, IRQ, AZE, SYR, TKM, BHR, and MNG are in both the high-intensity zone and low-efficiency zone. The task of reducing global carbon dioxide is enormous, and every member should assume his own responsibility, especially these nine countries. They should take strong measures to save energy and reduce emissions. 
Table 6. Clustering by carbon emissions efficiency and intensity.

\begin{tabular}{|c|c|c|c|}
\hline $\begin{array}{l}\text { Clustering by } \\
\text { efficiency }\end{array}$ & Countries & $\begin{array}{l}\text { Clustering by } \\
\text { intensity }\end{array}$ & Countries \\
\hline $\begin{array}{l}\text { Carbon } \\
\text { emissions } \\
\text { high- } \\
\text { efficiency } \\
\text { zone }\end{array}$ & $\begin{array}{l}\text { USA, JPN, DEU, FRA, GBR, } \\
\text { ITA, MEX, ESP, TUR, NLD, } \\
\text { EGY, BEL, CHE, SWE, AUT, } \\
\text { HKG, SGP, CHL, NOR, PRT, } \\
\text { DNK, ISR, HUN, IRL, NZL, } \\
\text { LKA, SDN, HRV, GTM, ZWE, } \\
\text { SVN, CRI, PAN, URY, LUX, } \\
\text { CMR, NPL, BRN, BWA, GAB, } \\
\text { MLT. }\end{array}$ & $\begin{array}{l}\text { Carbon emissions } \\
\text { low-intensity zone }\end{array}$ & $\begin{array}{l}\text { USA, IND, JPN, DEU, FRA, GBR, } \\
\text { BRA, ITA, MEX, ESP, KOR, CAN, } \\
\text { TUR, IDN, AUS, NLD, ARG, THA, } \\
\text { PAK, EGY, COL, MYS, BEL, CHE, } \\
\text { SWE, PHL, AUT, VNM, HKG, GRC, } \\
\text { SGP, CHL, PER, NOR, PRT, BGD, } \\
\text { DNK, ISR, HUN, FIN, IRL, NZL, } \\
\text { MAR, SVK, ECU, LKA, DOM, SDN, } \\
\text { AGO, HRV, TUN, ETH, GHA, GTM, } \\
\text { TZA, LTU, ZWE, KEN, SVN, CRI, } \\
\text { PAN, URY, BOL, LUX, CMR, NPL, } \\
\text { LVA, PRY, ZMB, CIV, BRN, GEO, } \\
\text { BWA, ALB, CYP, HND, COD, MOZ, } \\
\text { GAB, SEN, TJK, ARM, NAM, KGZ, } \\
\text { BEN, ISL, COG, MLT, TGO. }\end{array}$ \\
\hline $\begin{array}{l}\text { Carbon } \\
\text { emissions } \\
\text { medium- } \\
\text { efficiency } \\
\text { zone }\end{array}$ & $\begin{array}{l}\text { IND, BRA, KOR, CAN, IDN, } \\
\text { IRN, AUS, SAU, POL, ARG, } \\
\text { THA, PAK, ZAF, COL, MYS, } \\
\text { PHL, VNM, ROU, GRC, PER, } \\
\text { CZE, BGD, QAT, FIN, KWT, } \\
\text { BLR, MAR, SVK, ECU, BGR, } \\
\text { OMN, DOM, TUN, GHA, } \\
\text { TZA, LTU, KEN, BOL, LVA, } \\
\text { PRY, BIH, ZMB, CIV, TTO, } \\
\text { EST, GEO, ALB, CYP, HND, } \\
\text { TJK, ARM, JAM, NAM, KGZ, } \\
\text { BEN, ISL, COG. }\end{array}$ & $\begin{array}{l}\text { Carbon emissions } \\
\text { medium-intensity } \\
\text { zone }\end{array}$ & $\begin{array}{l}\text { CHN, RUS, IRN, SAU, POL, NGA, } \\
\text { VEN, ROU, CZE, KWT, BLR, BGR, } \\
\text { OMN, LBN, YEM, JOR, BIH, EST, } \\
\text { MKD, JAM, MDA, SLV. }\end{array}$ \\
\hline $\begin{array}{l}\text { Carbon } \\
\text { emissions low- } \\
\text { efficiency } \\
\text { zone }\end{array}$ & $\begin{array}{l}\text { CHN, RUS, NGA, UKR, VEN, } \\
K A Z, U Z B, I R Q, A Z E, \text { AGO, } \\
S Y R, \text { ETH, TKM, LBN, YEM, } \\
\text { JOR, } B H R, C O D, M O Z, S E N, \\
\text { MKD, } M N G, \text { MDA, SLV, } \\
\text { TGO. }\end{array}$ & $\begin{array}{l}\text { Carbon emissions } \\
\text { high-intensity } \\
\text { zone }\end{array}$ & $\begin{array}{l}\mathrm{ZAF}, U K R, K A Z, \mathrm{QAT}, U Z B, I R Q \text {, } \\
A Z E, S Y R, T K M, B H R \text {, TTO, } M N G .\end{array}$ \\
\hline
\end{tabular}

Note: These countries in bold italic are in the low efficiency and high intensity zones.

The disparity in the results by clustering derives from the differing impacts of clustering by carbon emissions efficiency and carbon emissions intensity. The former is not equivalent to the latter. Instead, they represent two different indexes for measuring the performance of carbon emissions. The latter is measured with inputs considered, while the former is not. Compared with the former, the latter relies more strongly on low carbon policy making. 


\subsection{Convergence Analysis of ACECPI}

In order to analyze the convergence or divergence of CECPI during the period 1992-2009 we follow the kernel density estimation which is a probabilistic approach developed by Silverman, 1986 [23]. Let the density function of $\mathrm{X}$, the $\mathrm{p}$-dimension stochastic vector, be $f(x)=f\left(x_{1}, \ldots, x_{n}\right)$, then $X_{1}, X_{2}, \cdots, \mathrm{X}_{\mathrm{n}}$ are samples with independent and identical distribution. Silverman (1986) [23] suggested that a kernel density estimation be defined as follows:

$$
\hat{f}_{h}(x)=\frac{1}{n h} \sum_{i=1}^{n} K\left(\frac{x-X_{i}}{h}\right)
$$

where $\mathrm{K}$ is the Epanechnikov kernel function and $\mathrm{h}$ is the bandwidth of appropriate size.

We choose 1992, 1993, 1997, 2001, 2005, and 2009 as the years being investigated, and then calculate the accumulated CECPIs (ACECPIs) using Equation (10) below.

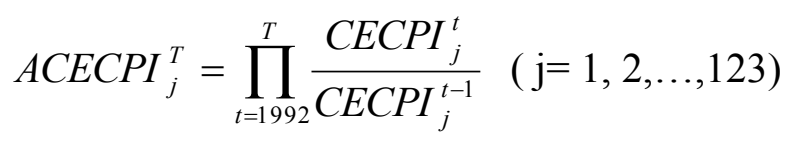

where $\mathrm{j}$ is the country under calculation and $\mathrm{T}$ is the year being investigated.

Based on the Equations (9) and (10), we work out the kernel density distribution of ACECPIs for the six years being investigated (Figure 2).

Figure 2. Kernel density distribution of ACECPIs.

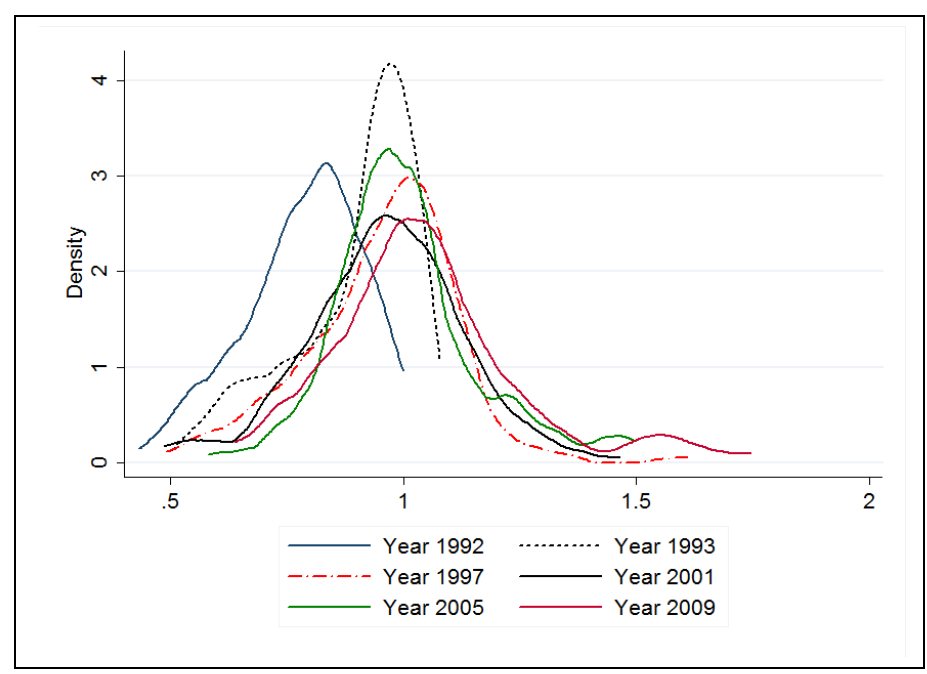

Figure 2 shows that the crests of the distribution curve for the ACECPIs of 123 countries during the years 1992-2009 remain in the lower CECPI throughout the period and shift further to the right, correspondingly. This indicates that more countries have low CECPIs, but the CECPIs of all countries are improving. Furthermore, there is a decline in crests, which suggests that the gap between these countries is narrowing. The trend of this distribution shows us that some countries have greatly improved their CECPI to a relatively higher level. With the gaps narrowing, it is easier for low efficiency countries to keep pace with high efficiency countries. 


\section{Conclusions}

The general methodology we have proposed in this paper takes the undesirable output into account. This allows an evaluated DMU to obtain projections of nearest targets and minimum distance from the strong efficient frontier. This methodology is first to measure environmental efficiency. Compared with traditional approaches, its advantage lies in achieving the optimum with less improvement in inputs and outputs.

Our findings have shown that among the top 10 CECPI countries, only the United Kingdom's GDP ranks among the top 10 while none of the remaining countries ranks in the top thirty. That is, the top 10 GDPs largely have lower CECPIs. Most developing countries have lower CECPIs than developed nations. Further, the inefficiency shares of $\mathrm{E}, \mathrm{K}$, and $\mathrm{Y}$ are declining while those of $\mathrm{L}$ and $\mathrm{b}$ are climbing.

By cluster analysis, 41 countries have relatively ideal CECPIs, while UKR, KAZ, UZB, IRQ, AZE, SYR, TKM, BHR and MNG should consider severe measures for energy savings and carbon emission reduction. The kernel density estimation shows that the gap in CECPIs among the 123 countries is narrowing, which will make it easier for low efficiency countries to overtake high efficiency countries.

The limitation of this study is that the (mSBM) measure is a non-parametric and deterministic frontier analysis method with no specific function and non-statistical properties. This restriction means that random factors are not considered.

The authors are grateful for the financial support provided by the National Social Science Foundation of China (11AJL011) and the Humanities and Social Science Foundation of the Ministry of Education (10YJA790029).

\section{Conflicts of Interest}

The authors declare no conflict of interest.

\section{References and Notes}

1. IPCC 2007. Available online: http://www.docin.com/p-731679800.html (accessed on 12 November 2013).

2. Grossman, G.M.; Krueger, A.B. Economic growth and the environment. Q. J. Econ. 1995, 2, 353-377.

3. Tevie, J.; Grimsrud, K.M.; Berrens, R.P. Testing the Environmental Kuznets Curve Hypothesis for Biodiversity Risk in the US: A Spatial Econometric Approach. Sustainability 2011, 11, 2182-2199.

4. Casler, S.D.; Rose, A. Carbon dioxide emissions in the US economy: a structural decomposition analysis. Environ. Resource. Econ. 1998, 11, 349-363.

5. Reinhard, S.; Lovell, C.A.K.; Thijssen, G.J. Environmental efficiency with multiple environmentally detrimental variables; estimated with SFA and DEA. Eur. J. Oper. Res. 2000, 2, 287-303.

6. Zhou, P.; Ang, B.W.; Poh, K.L. Slacks-based efficiency measures for modeling environmental performance. Ecol. Econ. 2006, 1, 111-118.

7. Guo, X.; Zhu, L.; Fan, Y.; Xie, B. Evaluation of potential reductions in carbon emissions in Chinese provinces based on environmental DEA. Energ. Pol. 2011, 5, 2352-2360. 
8. Zhang, Z.X. Macroeconomic effects of $\mathrm{CO} 2$ emission limits: A computable general equilibrium analysis for China. J. Pol. Model. 1998, 20, 213-250.

9. Kaya, Y.; Yokobori, K. Environment, Energy and Economy: Strategies for Sustainability. United Nations University Press: Tokyo, Japan, 1997.

10. Mandal, S.K.; Madheswaran, S. Energy use efficiency of Indian cement companies: a data envelopment analysis. Energ. Effic. 2011, 1, 57-73.

11. Halog, A.; Manik, Y. Advancing Integrated Systems Modelling Framework for Life Cycle Sustainability Assessment. Sustainability 2011, 2, 469-499.

12. Jahanshahloo, G.R.; Vakili, J.; Zarepisheh, M. A linear bilevel programming problem for obtaining the closest targets and minimum distance of a unit from the strong efficient frontier. APJOR 2012, 2, 1-19.

13. Zaim, O.; Taskin, F. Environmental efficiency in carbon dioxide emissions in the OECD: A nonparametric approach. J. Environ. Manag. 2000, 2, 95-107.

14. Ramanathan, R. A multi-factor efficiency perspective to the relationships among world GDP, energy consumption and carbon dioxide emissions. Technol. Forecast. Soc. Chang. 2006, 5, 483-494.

15. Zhou, P.; Ang, B.W.; Han, J.Y. Total factor carbon emission performance: A Malmquist index analysis. Energ. Econ. 2010, 1, 194-201.

16. Zhang, N.; Zhou, P.; Choi, Y. Energy Efficiency CO2 emission performance and technology gaps in fossil fuel electricity generation in Korea: A meta-frontier non-radial directional distance function analysis. Energ. Pol. 2013, 56, 653-662.

17. Lu, C.; Chiu, Y.; Shyu, M.; Lee, J. Measuring CO2 emission efficiency in OECD countries: Application of the Hybrid Efficiency model. Econ. Model. 2013, 32, 130-135.

18. Wang, K.; Yu, S.; Zhang, W. China's regional energy and environmental efficiency: A DEA window analysis based dynamic evaluation. Math. Comput. Model. 2013, 58, 1117-1127.

19. Aparicio, J.; Ruiz, J.L.; Sirvent, I. Closest targets and minimum distance to the Pareto-efficient frontier in DEA. J. Prod. Anal. 2007, 3, 209-218.

20. Tone, K. A slacks-based measure of efficiency in data envelopment analysis. Eur. J. Oper. Res. 2001, 3, 498-509.

21. Cooper, W.W.; Ruiz, J.L.; Sirvent, I. Choosing weights from alternative optimal solutions of dual multiplier models in DEA. Eur. J. Oper. Res. 2007, 1, 443-458.

22. SPSS, version 17.0; SPSS Inc.: Chicago, IL, USA, 2009.

23. Silverman, B.W. Density estimation for statistics and data analysis; CRC Press: Florida, FL, USA, 1986.

\section{Appendix}

The 123 countries (or regions) and their country codes are: United States (USA), China (CHN), India (IND), Japan (JPN), Germany (DEU), Russian Federation (RUS), France (FRA), United Kingdom (GBR), Brazil (BRA), Italy (ITA), Mexico (MEX), Spain (ESP), Korea, Rep. (KOR), Canada (CAN), Turkey (TUR), Indonesia (IDN), Iran, Islamic Rep. (IRN), Australia (AUS), Saudi Arabia (SAU), Poland (POL), Netherlands (NLD), Argentina (ARG), Thailand (THA), Pakistan (PAK), South Africa (ZAF), Egypt, Arab Rep. (EGY), Colombia (COL), Malaysia (MYS), Belgium 
(BEL), Nigeria (NGA), Ukraine (UKR), Switzerland (CHE), Sweden (SWE), Philippines (PHL), Austria (AUT), Vietnam (VNM), Venezuela, RB (VEN), Romania (ROU), Hong Kong SAR, China (HKG), Greece (GRC), Singapore (SGP), Kazakhstan (KAZ), Chile (CHL), Peru (PER), Norway (NOR), Czech Republic (CZE), Portugal (PRT), Bangladesh (BGD), Qatar (QAT), Denmark (DNK), Israel (ISR), Hungary (HUN), Finland (FIN), Kuwait (KWT), Uzbekistan (UZB), Ireland (IRL), Belarus (BLR), Iraq (IRQ), New Zealand (NZL), Morocco (MAR), Slovak Republic (SVK), Ecuador (ECU), Sri Lanka (LKA), Bulgaria (BGR), Oman (OMN), Dominican Republic (DOM), Azerbaijan (AZE), Sudan (SDN), Angola (AGO), Syrian Arab Republic (SYR), Croatia (HRV), Tunisia (TUN), Ethiopia (ETH), Turkmenistan (TKM), Ghana (GHA), Guatemala (GTM), Tanzania (TZA), Lithuania (LTU), Lebanon (LBN), Zimbabwe (ZWE), Kenya (KEN), Yemen, Rep. (YEM), Slovenia (SVN), Costa Rica (CRI), Panama (PAN), Uruguay (URY), Bolivia (BOL), Luxembourg (LUX), Cameroon (CMR), Nepal (NPL), Latvia (LVA), Jordan (JOR), Paraguay (PRY), Bosnia and Herzegovina (BIH), Zambia (ZMB), Cote d'Ivoire (CIV), Brunei Darussalam (BRN), Bahrain (BHR), Trinidad and Tobago (TTO), Estonia (EST), Georgia (GEO), Botswana (BWA), Albania (ALB), Cyprus (CYP), Honduras (HND), Congo, Dem. Rep. (COD), Mozambique (MOZ), Gabon (GAB), Senegal (SEN), Macedonia, FYR (MKD), Tajikistan (TJK), Armenia (ARM), Mongolia (MNG), Jamaica (JAM), Moldova (MDA), Namibia (NAM), Kyrgyz Republic (KGZ), Benin (BEN), Iceland (ISL), Congo, Rep. (COG), Malta (MLT), El Salvador (SLV), Togo (TGO).

(C) 2013 by the authors; licensee MDPI, Basel, Switzerland. This article is an open access article distributed under the terms and conditions of the Creative Commons Attribution license (http://creativecommons.org/licenses/by/3.0/). 